\title{
Legal Regulations of Flexible Working in Jordan
}

\author{
Ibrahim Saleh Al Sarairah $^{1}$ \\ ${ }^{1}$ Comparative Law Department, Sheikh Noah's College of Sharia and Law, University of Islamic Sciences, \\ Amman, Jordan \\ Correspondence: Ibrahim Saleh Al Sarairah. E-mail: Dr.ibraheimsarairah@yahoo.com
}

Received: May 9, 2018 Accepted: May 22, $2018 \quad$ Online Published: June 22, 2018

doi:10.5539/ass.v14n7p70

URL: https://doi.org/10.5539/ass.v14n7p70

\begin{abstract}
The flexible working system in Jordan for the year 2017 represents a qualitative leap in the field of work, for providing an easy work for the workers, especially the working woman, which enables her to enter the labor market. However, this system has many conditions that must be met in flexible working contract in terms of a written agreement between the worker and the employer and the time limit and specified some categories that are subject to flexible working.

The flexible working system collides with some general principles of the labor law, such as the legal subordination, and the disciplinary authority of the employer in imposition of disciplinary sanctions in the event that the worker violates the flexible working rules.

The study concluded with a number of results, the most important is that the flexible working contract is a formal contract in which the writing is required. The Jordanian legislator ruled out the event from the workers who are subject to the flexible working system.

The most important recommendations were, It is necessary explicitly state that the rights of the worker may be established in the flexible working contract by all means of legal proofs. If the contract was not issued in writing, it is necessary to stipulate that the wage might be determined in the flexible working contract on a daily or weekly basis.
\end{abstract}

Keywords: flexible working, flexible working contract, legal subordination, disciplinary authority, wage

\section{Introduction}

The idea of flexible work started in the advertising companies and commercial companies that distribute huge amounts of commercial advertisements on houses and mail boxes. These companies were previously costing their employees in their homes by filling postage stamps or writing the titles on the advertisements, thus reducing the cost of labor and warehouse and office costs. Enterprises American companies that employ women for sale through the service "door to door" and thus began the introduction of the system (flexible working hours), which facilitates the selection of employees work hours and start and end in coordination with management. ${ }^{(1)}$

Since the rules of the Labor Law are characterized by being social rules in the sense that they reflect the society's creed and the principles and ethics prevailing in it, because of the impact that this law and the regulations issued thereunder have left on the life of the entire society. ${ }^{(2)}$

In addition to the real nature of the rules governing labor contracts, since the inception of this legislation from the beginning to take care of the interests of workers of different categories. ${ }^{(3)}$

Therefore, the legislator must respond to the circumstances of specific groups and introduce the flexible work organization of the Jordanian legislation. The flexible work represents a philosophy for organizing the business, not just a technical procedure carried out by institutions.

\subsection{Significance of the Study}

The importance of the research is to demonstrate the extent to which the flexible work system can develop the work, which is in response to the development of the labor market, by empowering women from the labor market. Mobility to and from the labor market may be an obstacle to the work of women in Eastern societies.

\subsection{Research Problem}

The extent to which the provisions of that system are in conformity with the Labor Code, since the Labor Code 
regulates the working hours and regulates the disciplinary authority of the employer. Where the legal questions that this research came to answer are what is a flexible labor contract? And which categories would you be subject to? What forms of flexible work in Jordanian legislation, and what are the aspects of legal dependence in this contract, and whether the employer in the flexible employment contract has disciplinary authority in the face of the worker?

\section{Research Methodology}

The comparative descriptive analytical approach will be used. Through the statement of the provisions of the system and its analysis and compare them with some laws and comparative systems.

\subsection{Research Plan}

The research will be divided into two sections: the first topic, which talks about the flexible work, and the second, which talks about the effects of organizing flexible work.

\subsection{The First Topic: What Is Flexible Work}

In this section, the flexible work will be defined, in terms of its concept, characteristics, image, and categories covered by its provisions, as follows:

The first requirement: the concept of flexible work

The flexible work system defined flexible work as "any intellectual or physical effort the worker makes for a wage within one of the forms of flexible labor contract specified in this system ${ }^{(4)}$

We note that this definition is always consistent with the definition of the work contained in the Jordanian Labor Law, and the Jordanian legislator did not take other legislative measures in the absence of a definition of flexible work, since some legislations, including the Saudi Labor Law, only defined flexible work images without a comprehensive definition of that Pictures. ${ }^{(5)}$

The legislator defined the flexible labor contract as "a written agreement whereby the worker undertakes to work under the flexible contract of employment to work with the employer under his supervision and management in return for a wage. The contract is fixed-term or indefinite or specific or non-specific work in accordance with flexible forms of work specified in this system.

Through this definition we can conclude the following:

The flexible work contract is a formality contract in which writing is required, and writing here is, in our opinion, a condition of meeting, not a requirement of proof, but in our view, the fact of the work in general is a material fact that can be proved by all means of proof even if the work is a form of flexible work. Thus, it was better for the legislator and the Jordanian labor law to explicitly state that "a worker may prove his rights by all means of legal proof if the contract is not written in writing ${ }^{(6)}$

1. In order for the contract to be a flexible contract of work, it is necessary to have two elements (supervision and management) by the employer, in contrast to the normal contract of work in which one of them is available (supervision or administration).

In reference to the same article of this system we find that the definitions of the worker and the employer and pay are very similar to their definitions contained in the Jordanian Labor Code with some differences and can be summarized as follows:

1 - in the definition of the worker: was deleted the factor in the experiment and Hasnaifal Jordanian legislator where it is known that the purpose of the condition of the experiment is to verify the employer of the efficiency of the worker and his ability to perform the work is difficult to verify in case the worker works according to a picture of work The legislator excluded the event from the workers who are subject to the flexible work system. It may be wise not to include events in flexible work in the first and second categories of categories subject to the provisions of the system, namely the category of workers who have spent more than 3 consecutive years with the employer, The second category includes a worker who has a family responsibilities The other categories may apply to the event worker who - in our view - is the most appropriate worker whose interests should be considered and included in the flexible work, but the first was to come to define the worker: that every natural person is better than the formula of every male or female.

In the definition of the employer: The Jordanian legislator did not add to the definition of the employer as the employer in the institutions that follow the flexible work system.

In the definition of pay: as in the flexible work system that the wage payable to the worker in the flexible labor contract is determined in proportion to the amount of time or work performed during the month, ie - the concept 
of the violation - can not determine the wage in the contract flexible work on a daily basis or weekly, And we do not know the wisdom of that, but it was better to legislate to include this in the definition of wages. ${ }^{\left({ }^{(7)}\right.}$

The second requirement: the importance of flexible work ${ }^{(8)}$

There are several factors that may lead organizations to resort to a flexible system of work: change in the organizational environment of the knowledge society, modern technologies that are accessible to all, policies of institutions that are more adapted to the spirit of the times, and the tendency of workers and employers to such unconventional ideas.

The importance of a flexible labor contract can be summarized as follows:

For the worker:

A. Balance between comfort and work by giving workers freedom of choice.

B. Motivate employees working in accordance with this system and encourage their retention, and empowering women from the labor market, considering that going and going to the labor market may be a hindrance.

$\mathrm{T}$ - reduce the work pressure that the worker is exposed to.

W - Minimize the bureaucracy and control the employer is unnecessary or unnecessary as much as possible.

(C) Minimize the need of workers for annual or sick leave.

Increasing employment opportunities.

As for employers

A - Increase the ability of companies and institutions to serve their customers, by reducing the time taken to respond to the customer request.

B Raise the efficiency of the services provided and improve productivity by solving problems through workers who do not combine the boundaries of each according to their experience.

Increasing the efficiency of the internal and external communication and communication of the institution.

(D) Reduction of expenses and expenses.

C - Hearing the employers and workers and the working group at the institution to collect an individual to organize their work in the service of achieving the objectives of the institution regardless of the actual location and borders.

The size of absence among flexible workers is much lower than that of ordinary workers.

To work in emergency situations and climatic conditions, and to reduce the movement of work, which leads to reduced pollution during travel time.

Knowing that the work contract may be detrimental to both the employer and the worker is:

Increasing costs in terms of infrastructure of modern technologies, increasing the volume of unprotected work, flexible work may lead to increased social differences and increase the gender gap, and some see that flexible work may lead to the extension of work for every minute of the day and week. ${ }^{(9)}$

Third requirement: Flexible work images and categories covered by its provisions

In the event that the labor contract is converted into a flexible contract in accordance with the nature of the work, the employer shall submit an application to the employer. The system is also in a single specific case, namely, the conversion of the normal contract of employment into a flexible work contract Which raises the question of the possibility of signing a contract of flexible work from the beginning of work with the employer without conversion and harm in that, stressing that this question does not apply to the first category of categories provided for in the system. Therefore, we would like the Jordanian legislator and the text to explicitly answer these questions.

\subsection{The Categories Covered Are (10) $^{.}$}

1. The worker who spent in service with the employer three consecutive years.

The worker who has family responsibilities includes the pregnant woman, the worker who takes care of a child or the care of a member of the family or the care of the elderly due to disability or illness. In this case, the position of the Jordanian legislator differed from what was stated in the Jordanian Labor Law. On vacation to take care of her children to have two or more children ${ }^{(11)}$

2. The regular worker in university studies. 
3. Working with people with disabilities.

\subsection{As for the Flexible Work Images in Jordanian Legislation, They Are. ${ }^{(12)}$}

1- Working part time: The employee has the right to reduce the working hours after the approval of the employer if the nature of the work permit it.

2- Working within flexible hours: The worker has the right and after the employer's approval to distribute the specified working hours daily and in accordance with the needs of the worker, provided that the total number of hours worked on a daily basis is not less than the normal working hours of the worker

3- Intensive working week: The employee has the right and after the employer's approval to distribute the weekly working hours on the number of days less than the number of normal working days in the facility, but not to exceed eleven hours a day.

4- Flexible Year: After the agreement with the employer, the worker shall be entitled to distribute the annual working days on specified months of the year provided that the provisions of the law do not exceed.

5- Work remotely: where the completion of work remotely and so after the consent of the employer and without the need for the presence of the worker in the workplace.

The system defines how the work can be transformed into flexible work on one of these images, at the request of the worker from the above categories to the employer, and not the employer to impose the conversion of the status of a particular working contract without his consent, under any action that may impair the rights Which raises the question that in the event that the employer's sole will to convert a contract of employment into a flexible contract of employment without detracting from the rights of the worker provided for in the law, does this result in nullification also, or that the invalidity is the penalty of a decision for actions that detract from the rights Working only without the same flexible work contract. ${ }^{(13)}$

However, a worker whose contract is transferred to a flexible employment contract may return to the non-flexible work order with a request to the employer with the consent of both parties. ${ }^{(14)}$ We also ask the legislator to set a time limit for such a request for stability.

The provisions of the Flexible Work Regulations of 2018 have been observed, but what is taken is that in all its provisions, the employer has been given authority and the best proof of that is provided in Article 4 of these Instructions ", which gave the employer the right to reject a request to convert a contract of employment into a flexible employment contract The assignment of the contract is a financial cost, if the result is a negative impact on the quality and performance of the work, if the print job of the worker requires his daily presence in the workplace and therefore we find that these instructions were given to the employer to reject the request without the need to form a committee so that is the ruling on So. ${ }^{15}$

\subsection{The Second Topic: The Effects of Flexible Organization of Work}

The flexible work contract is a binding contract for the two sides, which arranges obligations on both the working parties and the employer, since all that the employer has in the face of the employee is his right to supervision and management and, most importantly, the employer has disciplinary authority in the face of the worker $_{(16)}$, And we will discuss in this subject the subject of legal dependency and its relationship to the flexible contract of work in the first demand, in addition to the authority of the employer disciplinary in the contract of flexible work in the second demand:

The first requirement: flexible work and its relationship to legal dependency

Legal subordination means that "the worker is subject to the authority of the employer during the execution of the work so that the employer can direct the worker to the worker and the worker must obey these orders or the employer has the right to impose disciplinary sanctions on him. ${ }^{(17)}$

Since the element of legal dependence is the basis for distinguishing the labor contract from other contracts, and since the flexible contract of employment is a contract of work at the beginning but in a different way, it is necessary to highlight the elements of supervision and management ${ }^{(18)}$

Through the definitions, we observe the legislator's requirement that there be legal dependence on the operation of the flexible labor system.

Supervision shall mean: "The employer shall have the right to determine the working conditions of the worker and monitor him from the extent of his compliance with the implementation of these conditions, and the signing of disciplinary sanctions in case of non-compliance even if the employer does not have the technical expertise in 
how to carry out the work. ${ }^{(19)}$

Management refers to: "the right of the employer to intervene in the manner in which the work is carried out, ie, the existence of a technical dependency of the employer. ${ }^{(20)}$ "

In fact, flexible work does not lose the employer's legal dependency on the worker, since the mere absence of a worker at the workplace does not mean that he can not be supervised and managed.

The manifestation of legal dependency in the texts of the flexible work system is manifested by the limited work of the worker who is required to convert his contract into a flexible work contract with the consent of the employer, in addition to the minimum working hours specified in the Labor Law ${ }^{(21)}$, And the conversion of the contract of employment into a flexible contract does not mean that the worker loses the rights he enjoys under the labor law, knowing that the wage and the worker's entitlement to sick and annual sick leave and other are determined on the basis of a percentage of working hours by agreement between the worker and the employer. ${ }^{(22)}$

\subsection{The Second Requirement: Flexible Work and Its Relation to the Disciplinary Authority of the Employer}

The disciplinary authority of the employer shall be defined as: "The right of the employer to sign a disciplinary penalty for the worker even if the violation does not cause harm to the employer in an affirmation of the work system in the establishment and the duties of the worker and deter the offender and other workers from committing the same worker ${ }^{(23) "}$

The disciplinary authority aims at denying the worker as a result of breaching his obligations, protecting the working group and ensuring respect for the workers' system of work and the implementation of the obligations arising from the contract. ${ }^{(24)}$

The employer shall be punished by a fine of not less than (300) dinars and not more than (500) dinars, JD The court may not reduce the sentence to a minimum or take mitigating circumstances and increase the penalty in case of repetition. ${ }^{(25)}$

In addition to the inadmissibility of taking disciplinary action or imposing a fine on the worker for an offense not provided for in the sanctions list adopted by the Minister of Labor or his authorized representative. (26)

Since no disciplinary sanction may be imposed on the worker in a contract of employment or flexible employment contract, unless there is a disciplinary sanction list approved by the Minister of Labor, the flexible work system requires the employer to amend the internal regulations of the institution in accordance with the flexible work system, Determining the procedures for transferring the status of the contract of employment to a flexible work contract in accordance with the internal rules of the establishment. ${ }^{(27)}$

The legal subordination in the contract of employment and the flexible work contract is the basis of the disciplinary authority. Under the subordination, the employer issues orders and directions for the execution of the work. The disciplinary authority represents the basis of the worker's compliance with these orders , ${ }^{(28)}$ And therefore the imposition of disciplinary sanction by the employer on the worker in the flexible labor contract is a must in accordance with the rules of procedure of the institution that follows the flexible work system to the worker who violates his obligations, but it differs from what is considered irregularities in the contract of flexible work according to flexible work images, For the usual violations of the contract of employment.

\subsection{There Are Several Types of Mistakes That a Worker May Make: ${ }^{(29)}$}

(A) Disciplinary errors relating to work schedules.

(B) disciplinary errors relating to the performance of the work;

(C) Disciplinary errors related to the work system.

(D) disciplinary errors related to the conduct of the worker.

\section{Conclusion}

After completing our research entitled "Legal Organization for Flexible Work", we reached the following conclusions and recommendations:

\section{Results}

1. The definitions in the flexible labor system are similar to those of the worker, the worker, the employer and the wage, with some minor differences added by the legislator to the flexible nature of the work.

2. A flexible contract of employment is a formality contract in which writing is required.

3. The legislator excluded the event from the workers to whom the flexible working system applies. 
4. The wage due to the worker in the flexible labor contract is determined in proportion to the amount of time or work performed during the month.

5. The flexible labor contract shall be beneficial to both the worker and the employer.

6. The Jordanian flexible labor system shall be limited to specific categories. If it wishes to convert the contract of employment into a flexible work contract in accordance with the nature of the work, it shall submit an application to the employer.

7. There are only five images in Jordanian legislation through which flexible work can be practiced.

8. By defining the flexible labor contract, we observe the legislator's requirement that the legal provisions of the flexible labor system be available and that the legislator does not only have one of the elements of supervision and management in the same way as the work contract.

9. The legal subordination in a flexible employment contract is the basis of the employer's disciplinary authority, since under this subordination the employer issues orders and instructions for the performance of the work and the representation of the disciplinary authority as the basis for the worker's compliance with such orders.

\section{Recommendations}

1. It is necessary to state explicitly that the rights of the worker may be established in a flexible employment contract by all means of legal proof if the contract is not written in writing.

2. The legislator emphasizes the requirement that the contract be a flexible contract of work, provided that the elements of supervision and management are available to the employer, and we believe that it is better to include the two elements as a choice rather than a combination, in order to protect the worker's rights.

3. It must be necessary to stipulate that the determination of wages in the contract of flexible work on a daily basis or weekly.

4. The need to stipulate the possibility of signing a flexible labor contract from the beginning of work with the employer without conversion.

5. The legislator must intervene and stipulate that if the flexible employment contract is valid, the employer will voluntarily transfer the contract of employment to a flexible employment contract, without derogating from the worker's rights stipulated in the law.

6. Some of the legislation, including the US, forced the worker, even remotely working to attend the headquarters of the company twice a week for the purpose of continuing contact with the employer, and some other legislation, such as Saudi legislation imposed obligations on the employer who employs workers flexibly, and we wish the Jordanian legislator revenues such as These texts to adjust the work.

7. The instructions for the flexible work of 2018 should include the formation of a tripartite committee consisting of (the representative of the employer, the representative of the trade union and the representative of the Ministry of Labor) for the purpose of determining the acceptance or rejection of the request to convert a contract of employment into a flexible work contract.

\section{References}

Al-Ahwani, H. Al-D. (1991). Explanation of the Labor Law.

Hamouri, E. (2001). Women and Children's Rights. Yarmouk University.

Khalifa, A. A. A. M. (2004). General Provisions of the Individual Work Contract (1st ed.).

Maghrabi, J. M. A. Explanation of the provisions of the Labor Law (1st ed.). House of Culture for Publication and Distribution.

Rahman, A. S. A. (2005). Explanation of the new labor law. Knowledge Facility, Alexandria.

Ramadan, S. (2004). Waseet in explaining the Labor Law. Amman: House of Culture.

Shanab, A. A. (2001). Explanation of Labor Law. Dar Al-Thaqafa, Amman.

Shanab, M. L. General Principles of Labor Law.

\section{Messages}

Issa, S. M. (2013). Employer's authority to identify disciplinary errors of the worker "Studied in the Jordanian Labor Law" (Master Thesis). Yarmouk University.

Al-Hamoud, L. S. (2012). Disciplinary Controls for the Employer (Master Thesis). Beirut University. 


\section{Legal Research}

Distance Learning - Media Production Center Studies Series - King Abdul Aziz University www.kau.edu.sa/F

\section{Margins}

(1) Distance Learning - Series Studies Center Media Production - King Abdul Aziz University.

(2) Jafar Mahmoud Al Maghrabi - Explain the provisions of the Labor Law - Department of Culture for Publishing and Distribution - First Edition-2016-p. 21.

(3) Hossam al-Din al-Ahwani, Explanation of Labor Law, 1991, p. 7.

(4) Article (2) of the Flexible Labor Law No. (22) for the year 2017, published on the number (5450) dated $16 / 3 / 2017$.

(5) Ministerial Resolution issued by the Saudi Ministry of Labor No. 792 dated 12-2-1436H.

(6) Article (15) of the flexible work system No. (26) for the year (2017).

(7) Article (6) of the flexible work system No. (22) for the year (2017).

(8) Distance Learning - Media Production Center Studies Series - King Abdulaziz University. Ibid., P.4.

(9) Distance Learning - Media Production Center Studies Series - King Abdul Aziz University - previous reference, p. 15

(10) Article (3) of the Flexible Labor Law No. (22) for the year 2017.

(11) Essam Hamouri, Women and Children's Rights, Yarmouk University, 2001, p. 31.

(12)Article (4) of the Flexible Labor Law No (22) for the year 2017.

(13) Article (5) of the Flexible Labor Law No. (22) for the year 2017.

(14) Article (5) of the Flexible Labor Law No. (22) for the year 2017.

(15) Instructions for flexible work for the year 2018, published in the Official Gazette No. (5509), dated 1/4/2018 from 1982 to 1984 .

(16)Khalifa, A. A. A. M. (2004). General Provisions of the Individual Work Contract (1st ed.).

(17) Sayed Ramadan - Waseet in explaining the Labor Law - House of Culture - Amman - 2004 - p16.

(18) Article (2) of the Flexible Labor Law No. (22) for the year 2017.

(19) Mohammed Labib Shanab, General Principles of Labor Law, (dn), (DT), p. 17.

(20) Ahmed Abu Shanab, Explanation of Labor Law, Dar Al-Thaqafa, Amman 2001, p. 93.

(21) Articles (2-4) of the Flexible Labor Law No (22) for the year 2017.

(22) Articles (6-7) of the Flexible Labor Law No (22) for the year 2017.

(23)Al-Hamoud, L. S. (2012). Disciplinary Controls for the Employer (Master Thesis, p. 4). Beirut University.

(24)Rahman, A. S. A. (2005). Explanation of the new labor law, Knowledge facility, Alexandria, p. 93.

(25) Article (48) of the Jordanian Labor Law No. (26) for the year (2010).

(26) Articles (55-77) of the flexible work system No. (26) for the year (2010).

(27) Articles (10-12) of the Flexible Labor Law No (22) for the year 2017.

(28) Saleh Mohammed Issa - The Employer's Authority in Determining the Disciplinary Errors of the Employee "Study in Jordanian Labor Law" - Master Thesis - Yarmouk University - 2013, p. 18.

(29) Hammam Mohamed Mahmoud, Labor Law, Dar al - Maarefah University, Alexandria, 2005, p. 7.

\section{Copyrights}

Copyright for this article is retained by the author(s), with first publication rights granted to the journal.

This is an open-access article distributed under the terms and conditions of the Creative Commons Attribution license (http://creativecommons.org/licenses/by/4.0/). 